\title{
Compositional analysis of archaeal communities in high and low microbial abundance sponges in the Misool coral reef system, Indonesia
}

Ana Rita Moura Polónia, Daniel Francis Richard Cleary, Francisco José Riso da Costa Coelho, Leontine E. Becking, Nicole Joy de Voogd, Abdul Hamid A. Toha \& Newton Carlos Marcial Gomes

To cite this article: Ana Rita Moura Polónia, Daniel Francis Richard Cleary, Francisco José Riso da Costa Coelho, Leontine E. Becking, Nicole Joy de Voogd, Abdul Hamid A. Toha \& Newton Carlos Marcial Gomes (2018) Compositional analysis of archaeal communities in high and low microbial abundance sponges in the Misool coral reef system, Indonesia, Marine Biology Research, 14:6, 537-550, DOI: 10.1080/17451000.2018.1498977

To link to this article: https://doi.org/10.1080/17451000.2018.1498977

曲 Published online: 03 Aug 2018.

Submit your article to this journal

Џ Article views: 45

View Crossmark data $₫$ 


\section{Compositional analysis of archaeal communities in high and low microbial abundance sponges in the Misool coral reef system, Indonesia}

Ana Rita Moura Polónia ${ }^{a}$, Daniel Francis Richard Cleary ${ }^{a}{ }^{a}$, Francisco José Riso da Costa Coelho ${ }^{a}$, Leontine E. Becking ${ }^{\mathrm{b}, \mathrm{c}, \mathrm{d}}$, Nicole Joy de Voogd ${ }^{\mathrm{b}, \mathrm{e}}$, Abdul Hamid A. Toha ${ }^{\mathrm{f}}$ and Newton Carlos Marcial Gomes ${ }^{\mathrm{a}}$

${ }^{a}$ Department of Biology, CESAM, Universidade de Aveiro, Aveiro, Portugal; ${ }^{b}$ Marine Biodiversity Group, Naturalis Biodiversity Center, Leiden, the Netherlands; ' ${ }^{C}$ Marine Animal Ecology, Wageningen, the Netherlands; ${ }^{d}$ Wageningen Marine Research, Den Helder, the Netherlands;

e Department of Environmental Biology, Institute of Environmental Sciences (CML), University of Leiden, Leiden, the Netherlands; ${ }^{\mathrm{f}}$ Fisheries Department, Papua University, Manokwari, Indonesia

\begin{abstract}
The high/low microbial abundance (HMA/LMA) dichotomy in sponges has been the subject of several studies over recent years, but few studies have analysed this dichotomy in terms of the sponge archaeal community and function. Using a 16S rRNA gene barcoded pyrosequencing approach and predictive functional analysis (PICRUSt) we compared the archaeal composition, richness and predicted function of one HMA sponge (Xestospongia testudinaria), one LMA sponge (Stylissa carteri) and one sponge species of unknown microbial abundance (Aaptos lobata). Although most of the archaeal sequences were assigned to the Crenarchaeota phylum, $S$. carteri had the highest percentage of sequences assigned to the Euryarchaeota phylum. Variation among sponge species explained $>85 \%$ of the variation in archaeal operational taxonomic unit (OTU) composition with each sponge species forming a distinct cluster. There were significant differences in predicted PICRUSt profiles among sponge species, suggesting that archaeal communities present in the studied sponge species may perform different functions. $X$. testudinaria and $A$. lobata were similar both in terms of OTU and KEGG orthologues composition, which may indicate that A. lobata is a HMA sponge. Additionally, some of the most enriched functions seem to be related to traits associated with high and low microbial abundance sponges.
\end{abstract}

\section{ARTICLE HISTORY}

Received 6 May 2017

Accepted 25 June 2018

Published online 3 August

2018

SUBJECT EDITOR

Mathias Middelboe

\section{KEYWORDS}

Archaea;16S rRNA gene; Aaptos lobata; HMA; LMA; PICRUSt

\section{Introduction}

Marine sponges are abundant, conspicuous sessile filter-feeders which harbour exceptionally high microbial (Archaea, Bacteria, and Eukaryota) densities (Diaz and Rützler 2001) within their mesohyl (Moitinho-Silva et al. 2014). By actively filtering large volumes of seawater, sponges contribute to benthicpelagic coupling and to water column composition alteration (e.g. secondary metabolite emanation, nutrient transformations; e.g. Bell 2008; Hoffmann et al. 2009; McMurray et al. 2014).

It has been assumed that part of the sponge functional repertoire has its origin not in the sponge itself but in its symbionts (e.g. Freeman and Thacker 2011; Ribes et al. 2012, 2015). Although not completely understood, due to the lack of studies of cultured endosymbionts, sponge-associated microorganisms are likely involved in nutrient transport and utilization (denitrification; nitrification, ammonium oxidation; carbon fixation); degradation of benzoic compounds; biosynthesis of secondary metabolites, antibiotics, cofactors and vitamins; redox sensing and response (Thomas et al. 2010; Fan et al. 2012; Hentschel et al. 2012). This functional repertoire benefits sponges by enhancing nutrient transfer; growth rates; aiding in metabolic waste processing; and providing protection against ultraviolet light and disease (Simpson 1984; Hentschel et al. 2002; Holmes and Blanch 2007; Erwin and Thacker 2008; Cebrian et al. 2011; Webster and Taylor 2012; Freeman et al. 2013). Additionally, these microbial-mediated metabolic functions play important ecological roles in coral reefs (e.g. Yahel et al. 2003; Hoffmann et al. 2009; de Goeij et al. 2013). Most microbial community studies of coral reefs have, however, focused on bacterial communities and less attention has been paid to archaeal communities. The same holds for sponge studies where the archaeal communities are still less studied, and thus less understood, than bacterial communities.

CONTACT Ana Rita Moura Polónia ritapolonia@gmail.com Department of Biology, CESAM, Universidade de Aveiro, Campus Universitário de Santiago, 3810-193 Aveiro, Portugal

(6) The supplementary material for this article (Table SI, Figures S1-S4) is available at https://doi.org/10.1080/17451000.2018.1498977

○ 2018 Informa UK Limited, trading as Taylor \& Francis Group 
Archaea members can dominate the microbial community in some sponges; for example, in Dragmacidon mexicana and Inflatella pellicula, Archaea account for more than $60 \%$ of all prokaryote cells (Preston et al. 1996; Jackson et al. 2013). Environmental factors may influence the sponge archaeal community (Turque et al., 2010), although there is some indication that the sponge archaeal community is related to sponge phylogeny (Schmitt et al. 2008; Steger et al. 2008). Zhang et al. (2014), studied sympatric sponges from the Mediterranean (collected in different seasons) and the Caribbean and showed specificity and persistence of archaeal symbionts within sponge species. One of the archaeal members most frequently associated with sponges belongs to the phylum Thaumarchaeota (Brochier-Armanet et al. 2008). This phylum includes members that are able to convert ammonium to nitrite and fix $\mathrm{CO}_{2}$ through ammonia oxidation. These characteristics suggest that Archaea may play critical roles in sponge hosts. These roles are likely linked with the sponge nitrogen metabolism and consequently with the nitrogen cycle (Zhang et al. 2014). However, the exact roles played by Archaea are still largely unknown.

Sponge species differ substantially in terms of the abundance of their microbial symbiont communities (e.g. Hentschel et al. 2003; Kamke et al. 2010; Bayer et al. 2014a). While some species have a number of microorganisms in the order of $10^{9}$ cells per gram wet weight of sponge ('high microbial abundance' HMA) others have a number of microorganisms similar to that found in the surrounding seawater ('low microbial abundance'- LMA), i.e. $10^{5}$ to $10^{6}$ cells per gram wet weight of sponge (Hentschel et al. 2012). This dichotomy is not only related to microbial abundance but also to sponge morphology and physiology, microbial diversity, microbial composition and microbial specificity (Erwin et al. 2015 and references therein). HMA sponges host highly diverse microbial communities (29 bacterial phyla; 2 Archaeal phyla; Bayer et al. 2014a); while LMA sponges, in contrast, host less diverse microbial communities that, to a certain extent, are similar to that of the surrounding seawater (Schmitt et al. 2007).

Some studies suggested that HMA and LMA sponges are dominated by distinct microbial members. Most of the HMA and LMA sponge indicators are, however, bacterial members (Bayer et al. 2014b; Moitinho-Silva et al. 2017). For Archaea, MoitinhoSilva et al. (2017), for example, reported that a Nitrosopumilus Operational Taxonomic Unit (OTU) was more abundant in LMA that in HMA sponges while Bayer et al. (2014b) reported that the archaeal amoA gene was slightly less abundant in HMA sponges. There are conflicting results among studies as to which factors better explain the microbial community composition of sponges; and it remains uncertain which is the most important factor influencing sponge microbial communities (host microbial abundance groups or host phylogeny; Blanquer et al. 2013; Schöttner et al. 2013).

The influence of microbial abundances in sponge function remains largely unknown as well as the ecological consequences of a functional HMA/LMA dichotomy. Bayer et al. (2014b) suggested that the HMA/LMA dichotomy extends to the functional gene level, however, few specific differences exist when individual genes were inspected. Most of the studies of sponge microbial HMA/LMA dichotomy have concentrated on bacterial communities, little is known about the existence of an archaeal dichotomy between HMA and LMA sponges.

In the present study, we assessed the composition of Archaea in three sponge species: the demosponges Stylissa carteri (Scopalinida: Scopalinidae; LMA; Giles et al. 2013), Xestospongia testudinaria (Haplosclerida: Petrosiidae; HMA; Gloeckner et al. 2014) and Aaptos lobata (Suberitida: Suberitidae; unknown microbial abundance), collected from three reef sites in the coral reef system of South East Misool, Papua, eastern Indonesia. Our main goals were to compare archaeal richness, composition and putative function between HMA and LMA sponges using a 16S rRNA gene barcoded pyrosequencing approach and a predictive metagenomic approach.

\section{Materials and methods}

\section{Data collection}

Triplicate samples of Stylissa carteri, Aaptos lobata and Xestospongia testudinaria were collected by snorkelling and scuba from 13 to 18 September 2013 in South East Misool, Raja Ampat region, West Papua province in Indonesia (Figure 1).

Stylissa carteri (Dendy, 1889) is a medium-sized bright orange sponge with a variable growth form (from thickly flabellate to bushy and digitate). It has a soft consistency and is easily torn with multiple small oscules distributed across its sponge body. Xestospongia testudinaria (Lamarck, 1815) is one of the largest known sponges and has a barrel to volcanoshaped morphology with a single large osculum. Its consistency is crumbly to stony and often very difficult to tear. Aaptos lobata (Calcinai et al. 2017) occurs in shallow coral reef ecosystems (de Voogd 


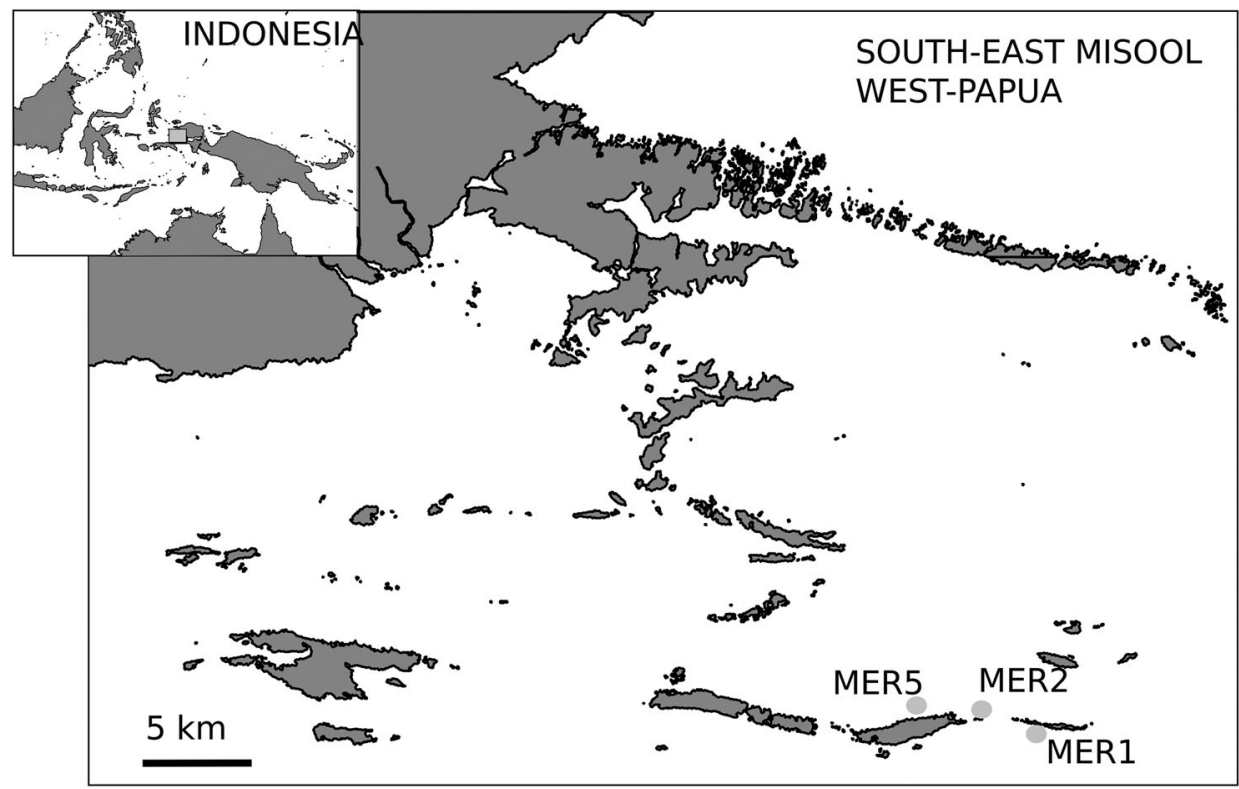

Figure 1. Map of the study area (Misool coral reef system) showing the study sites (Mer1; Mer2; Mer5).

and Cleary 2008) and has a thick irregular lobate growth form with numerous small oscules. The exterior is dark brown coloured and the interior is canary yellow. The sponge turns dark brown when taken out of the water. The consistency is very compact and firm, but easily cut. All three sponge species are common and have a wide distribution range in the Indo-Pacific region.

Sampling took place by the islands of Kalig and Boo (Mer1 ( $\left.2^{\circ} 13^{\prime} 6.18^{\prime \prime} \mathrm{S}, 130^{\circ} 33^{\prime} 52.74^{\prime \prime} \mathrm{E}\right)$, Mer2 (2 $2^{\circ} 13^{\prime} 7.32^{\prime \prime} \mathrm{S}$, $\left.130^{\circ} 33^{\prime} 36.66^{\prime \prime} \mathrm{E}\right)$, Mer5 ( $\left.2^{\circ} 13^{\prime} 12.00^{\prime \prime} \mathrm{S}, 130^{\circ} 31^{\prime} 37.00^{\prime \prime} \mathrm{E}\right)$ ) in the southern region. The locations had high coral cover along a slope or wall. One specimen of each sponge species was collected at the Mer1, Mer2 and Mer5 locations. Sponges were pre-identified in the field, photographed in situ and preserved in 95\% ethanol for morphological identification by $L B$ and $\mathrm{NdV}$ and deposited in the sponge collection of Naturalis Biodiversity Center, Leiden, the Netherlands. Samples of S. carteri, A. lobata and X. testudinaria were collected including segments of surface and interior in order to sample, as much as possible, the whole archaeal community (Cleary et al. 2013; Polónia et al. 2014). Stored in 95\% EtOH (Cleary et al. 2013), all samples were kept at temperatures lower than $4^{\circ}$ C. Once in the laboratory, samples were stored at $-80^{\circ} \mathrm{C}$ until DNA extraction.

\section{DNA extraction and pyrosequencing}

We isolated PCR-ready genomic DNA from S. carteri, A. lobata and $X$. testudinaria using the FastDNA ${ }^{\circledR}$ SPIN
Kit (MPbiomedicals) following manufacturer's instructions and previously published methods (Polónia et al. 2014, 2015). Succinctly, $500 \mathrm{mg}$ of sponge tissue were transferred to Lysing Matrix E tubes containing a mixture of ceramic and silica particles and lysed in the FastPrep ${ }^{\oplus}$ Instrument (Q Biogene) for $80 \mathrm{~s}$ at speed 6.0. Prior to 454 pyrosequencing, the amplicons of the archaeal 16S rRNA gene were obtained using the Archaea specific primers ARC344f-mod and Arch958Rmod (Pires et al. 2012). Using the amplicons of the archaeal 16S rRNA gene as template, the V3-V4 regions were amplified using barcoded fusion primers (524F-10-ext, Arch958R-mod; Pires et al. 2012). Following previous studies (Polónia et al. 2016, 2017), the barcoded pyrosequencing libraries were analysed using the QIIME (Quantitative Insights Into Microbial Ecology; Caporaso et al. 2010) software package (http://www.qiime.org/; last checked 20.3.2015). Briefly, in QIIME, fasta and qual files were used as input for the split_libraries.py script. Default arguments were used except for the minimum sequence length (set at $218 \mathrm{bp}$ after removal of forward primers and barcodes); backward primers were removed using the 'truncate only' argument and a sliding window test of quality scores was enabled with a value of 50 as suggested in the QIIME description for the scrip.

Greengenes (gg_13_5; http://greengenes.lbl.gov/ cgibin/nph-index.cgi) considers Thaumarchaeota (Brochier-Armanet et al. 2008, 2012) a class of the Crenarchaeota phylum; for this reason, throughout this study, we will follow the Greengenes taxonomy and refer Thaumarchaeota as a class. The DNA sequences 
generated in this study can be downloaded from the NCBI SRA: SRP069346.

\section{Predictive metagenome analysis}

To predict the metagenome of each sample, we used PICRUSt (Phylogenetic Investigation of Communities by Reconstruction of Unobserved States; Langille et al. 2013). PICRUSt is a bioinformatics tool that uses marker genes, in this case $16 \mathrm{~S}$ rRNA, to predict metagenome gene functional content. In order to test data for statistical significance, biological consistency and effect size relevance among sponge species we used the linear discriminant analysis (LDA) effect size (LEfSe) method (Segata et al. 2011). A detailed description of these methods has been published previously (Cleary et al. 2013; Langille et al. 2013; Polónia et al. 2014, 2015). PICRUSt results, instead of measuring actual gene presence/expression and function are predictive and thus provide information on putative enrichment and function. Care, thus, must still be taken in the interpretation of these results. LEfSe results are presented hierarchically using histograms (Segata et al. 2011). In addition to metagenomic data, we also obtained the weighted Nearest Sequenced Taxon Index (NSTI) scores for each sample. NSTI index is a way to evaluate the prediction accuracy of PICRUSt by averaging the branch length separating an OTU from a reference OTU (Langille et al. 2013).

\section{Statistical analysis}

Sequences not classified as Archaea were removed prior to statistical analysis. We used a self-written function in R (Gomes et al. 2010) to estimate rarefied OTU richness for each sample. Care, however, should be taken in the interpretation of richness estimates based on sequence data given the prevalence of sequencing errors (Edgar 2013). We assessed the distribution of OTUs in sponge species using a Venn diagram with the venn() function of the venneuler package in R. The OTU abundance matrix was $\log _{\mathrm{e}}(x$ +1 ) transformed (in order to normalize the distribution of the data) and a distance matrix was constructed using the Bray-Curtis index with the vegdist() function in the VEGAN package (Oksanen et al. 2009) in R. Sample diversity was assessed with rarefied species richness (S) (Gotelli and Colwell 2001) and Shannon's $\left(\mathrm{H}^{\prime}\right)$ diversity index (Shannon and Weaver 1949) using the diversity() and specnumber() functions of the Vegan package (Oksanen et al. 2009). The Chao1 richness estimator was calculated using the estimateR() function of the same package. Variation in OTU composition among sponge species (S. carteri, $A$. lobata and $X$. testudinaria) was assessed with Principal Coordinates Analysis (PCO) using the cmdscale() function in $\mathrm{R}$ with the Bray-Curtis distance matrix as input. Variation among sponge species was tested for significance using the adonis() function in VEGAN. In the adonis analysis, the Bray-Curtis distance matrix of species composition was the response variable with the sponge species as independent variable. The number of permutations was set at 999; all other arguments used the default values set in the function. Weighted averages scores were computed for OTUs on the first two PCO axes using the wascores() function in the vegan package. Detailed descriptions of the functions used here can be found in R (e.g. ?cmdscale) and online in reference manuals (http://cran.r-project. org/web/packages/vegan/index.html; 29.5.2015). The heatmap was generated using the function heatmap2 () in the R package gplots (http://www.cran.r-project. org/). The OTUs were log transformed and clustered according to their occurrence by UPGMA hierarchical clustering.

\section{Results}

The sequencing effort yielded 34,882 archaeal sequences, which were assigned to 38 archaeal OTUs after quality control, OTU picking and removal of chimeras and sequences not assigned to the archaeal domain. Of the total 38 OTUs, 12 had less than five sequences and of these four were singletons (one sequence per OTU).

\section{Higher taxon abundance}

Most of the sponge (Xestospongia testudinaria 97.79\%; Aaptos lobata - 97.48\%; Stylissa carteri $82.90 \%$ ) archaeal sequences were assigned to the Crenarchaeota phylum, Thaumarchaeota class, Cenarchaeales order (except $A$. lobata with $97.46 \%$ assigned to Cenarchaeales and $0.017 \%$ assigned to Nitrososphaerales order) and Cenarchaeaceae family (Figure 2; Figures S1 and S2). $82.50 \%$ of the S. carteri archaeal sequences were assigned to the Cenarchaeum genus while $97.78 \%$ and $96.48 \%$ of the $X$. testudinaria and A. lobata archaeal sequences respectively were assigned to the Nitrosopumilus genus.

OTU richness was highest in S. carteri and lowest in $X$. testudinaria (Figure S3). An asymptote was not achieved for any of the sponge species indicating that true richness was not assessed in the studied samples. However, due to the presence of amplification and sequencing artifacts, richness estimates based on 


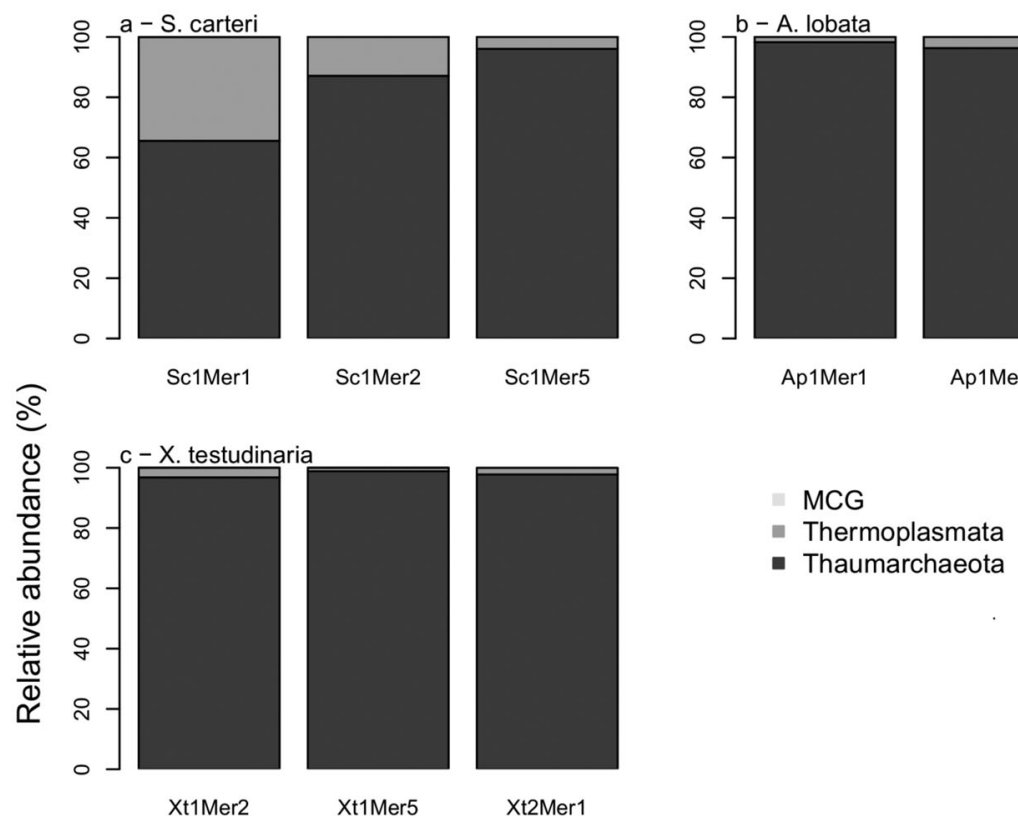

Figure 2. Mean relative abundance of the most abundant archaeal classes from S. carteri (Sc), A. lobata (Ap) and X. testudinaria (Xt).

454 sequencing should be treated conservatively (Edgar 2013).

Stylissa carteri from the site Mer1 had a lower percentage of sequences assigned to the Crenarchaeota phylum (65.55\%) when compared to the samples collected at the sites Mer2 and Mer5 (87.10\% and 96.05\%).

Most of the OTUs were shared among all three sponge species (15 OTUs; Figure 3). Stylissa carteri had eight exclusive OTUs; $A$. lobata six exclusive OTUs and $X$. testudinaria only one exclusive OTU. Four OTUs were exclusively shared between $A$. lobata and

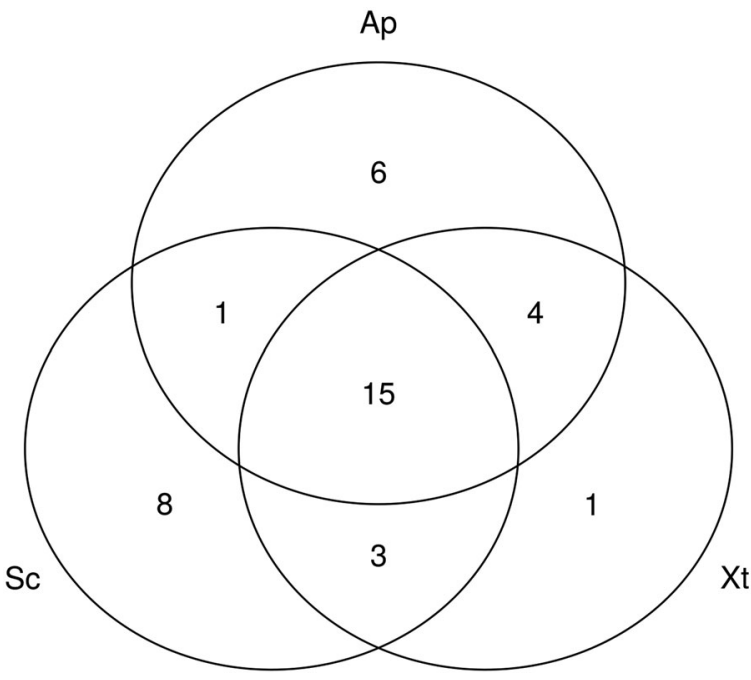

Figure 3. Venn diagram showing the amount of archaeal OTUs shared among the studied sponge species: $S$. carteri $(\mathrm{Sc})$, A. lobata (Ap) and $X$. testudinaria $(\mathrm{Xt})$.
$X$. testudinaria and only one OTU was exclusively shared between A. lobata and S. carteri.

The first (OTU-4), third (OTU-167) and fourth (OTU526) most abundant OTUs were assigned to the genus Nitrosopumilus and were closely related to archaeal phylotypes associated with the marine sponges Holoxea sp. (99.07\%) and Xestospongia muta (99.75\%; 99.01\%) (Figure 5; Table SI). The second most abundant OTU (OTU-3) was assigned to the Cenarchaeum symbiosum species and was closely related (100\%) to archaeal phylotypes associated with the marine sponge Phakellia fusca. The fifth most abundant OTU (OTU-2) was assigned to the Marine group II family and was closely related (100\%) to archaeal phylotypes associated with the coral Diploria labyrinthiformis (Figure 4; Table SI).

The Shannon's diversity index $(\mathrm{H})$, species richness (S), Pielou's evenness (J), Chao1 index (S.chao1), archaeal reads and nearest sequenced taxon index (NSTI) values for the sponge species sampled are shown in Table I. The highest mean values of species richness and Chao 1 estimate were detected in $S$. carteri samples while $X$. testudinaria samples had the highest mean values of $\mathrm{H}, \mathrm{J}$ and NSTI. Aaptos lobata had the highest mean number of archaeal reads.

\section{Importance of sponge species in structuring composition}

There was a highly significant difference in archaeal composition among sponge species $\left(F_{2,6}=17.11, P<\right.$ $\left.0.01, R^{2}=0.851\right)$. Variation among sponge species 


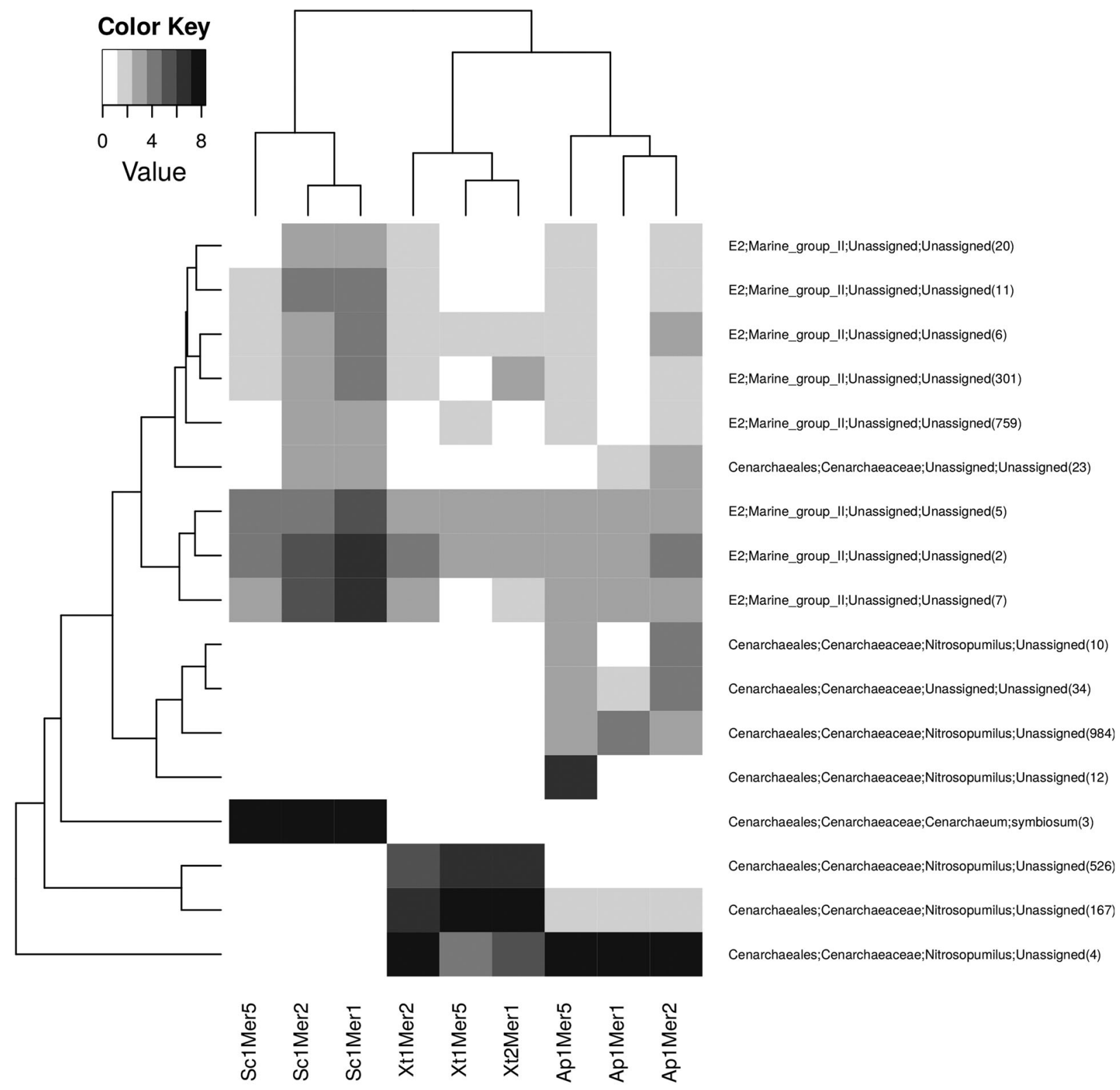

Figure 4. Heatmap showing the abundance of dominant OTUs (sequence reads $\geq 50$ sequences). Xt: X. testudinaria; Ap: A. lobata; Sc: S. carteri.

thus explained $>85 \%$ of the variation in archaeal composition. A PCO ordination (Figure 5) of the first two axes showed three distinct clusters representing samples from: (1) S. carteri; (2) A. lobata and (3) $X$. testudinaria. Axis 1 of the PCO ordination separated S. carteri samples from $A$. lobata and $X$. testudinaria samples. Axis 2 separated $X$. testudinaria samples from $A$. lobata samples with samples from $S$. carteri intermediate.

\section{Predictive metagenome analysis}

The PICRUSt and LEfSe analyses revealed significant differences in predicted enrichment among sponge samples for a number of functional top level categories (Figure S4), subcategories and individual pathways (Figures 6 and 7). Note that, as referred to above, since PICRUSt results are predictive, care must be taken in the interpretation of these results.

In terms of KEGG categories (Figure 7), S. carteri samples were significantly enriched for the metabolism of cofactors and vitamins, especially the porphyrin and chlorophyll metabolism and pantothenate and CoA biosynthesis pathways, oxidative phosphorylation and sulphur metabolism (energy metabolism pathways), aminoacyl-tRNA biosynthesis and basal transcription factors (genetic information processing pathways) and bacterial chemotaxis (cell motility pathway). 


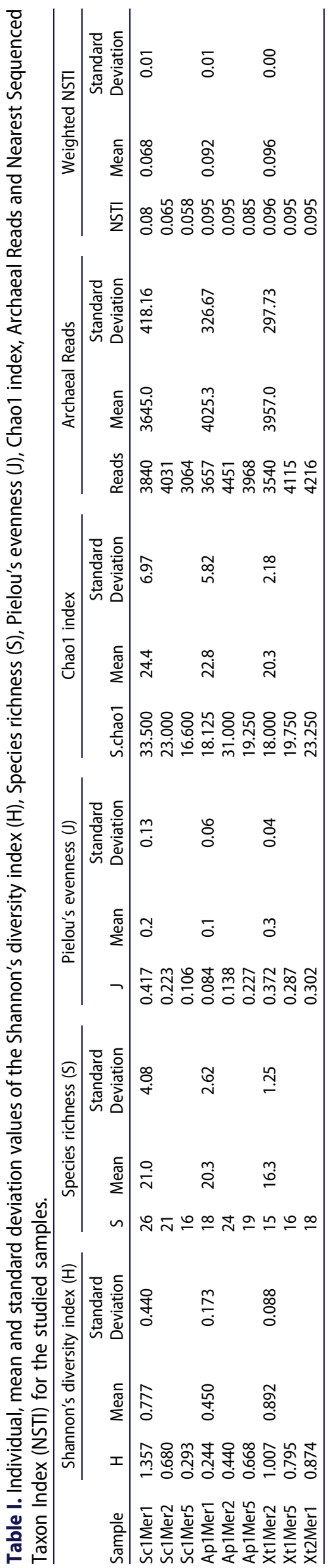

Xestospongia testudinaria samples were significantly enriched for several carbohydrate metabolism pathways, namely glycolysis/gluconeogenesis, citrate cycle (TCA cycle), pentose and glucuronate interconversions and pyruvate, propanoate, pentose phosphate and starch and sucrose metabolisms; additionally $X$. testudinaria samples were also enriched for the methane metabolism (energy metabolism), tryptophan metabolism, lysine degradation (amino acid metabolism), limonene and pinene degradation (metabolism of terpenoids and polyketides), chlorocyclohexane and chlorobenzene degradation and caprolactam degradation (xenobiotics biodegradation and metabolism) and the porphyrin and chlorophyll metabolism pathways (metabolism of cofactors and vitamins). Aaptos lobata samples, in turn, were significantly enriched for the phenylalanine metabolism pathway.

There was a significant difference among sponge species concerning KEGG ortholog (KO) composition $\left(F_{2,6}=30.08, \quad P<0.01, R^{2}=0.909\right)$. Variation among sponge species thus explained almost $91 \%$ of the variation in KO composition. A PCO ordination (Figure 8) of the first two axes showed two distinct clusters representing samples from: (1) S. carteri; (2) A. lobata and $X$. testudinaria. Axis 1 of the PCO ordination separated S. carteri samples from $A$. lobata and $X$. testudinaria samples. Axis 2 separated the $S$. carteri sample Sc1Mer5 from all the other S. carteri, A. lobata and $X$. testudinaria samples.

\section{Discussion}

The development of next-generation sequencing (NGS) technologies has allowed the characterization of sponge microbial communities at unprecedented levels. The sponge microbial community is now known to be diverse, stable and distinct from the surrounding environment (Hentschel et al. 2002, 2012). Despite little evidence of a clear dichotomy between HMA and LMA sponges, the microbial community of the HMA sponge has been characterized as highly abundant and diverse in contrast to LMA sponges, which host communities that are generally considered to be similar to that of the surrounding environment. Little is, however, known about the existence of an archaeal dichotomy between HMA and LMA sponges.

In line with several studies, the archaeal community of sponges was dominated by Crenarchaeota (Holmes and Blanch 2007; Lee et al. 2011; Polónia et al. 2014, 2015). Nevertheless, our results showed distinct archaeal communities among the studied sponge species but higher similarity between $X$. testudinaria and $A$. lobata. While $X$. testudinaria and A. lobata 

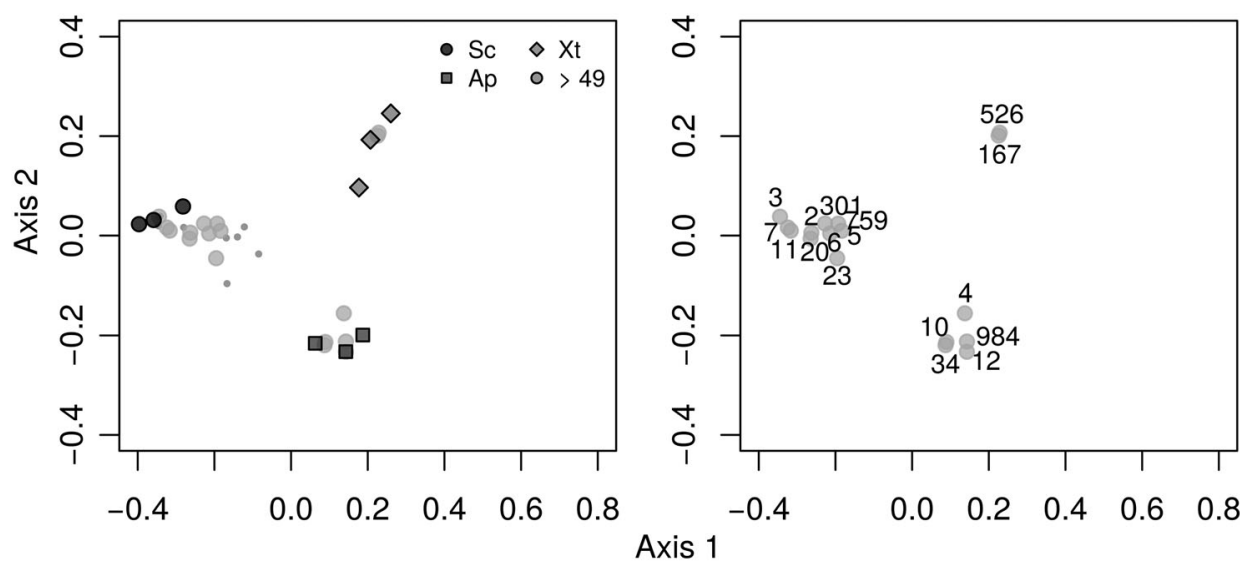

Figure 5. Ordination showing the first and second axes of the PCO analysis for archaeal OTU composition. Symbols represent samples from S. carteri (Sc), A. lobata (Ap) and X. testudinaria (Xt). Numbers refer to OTU numbers in Table SI. The small light grey circles represent OTUs with $<49$ sequences while the larger light grey circles represent OTUs $\geq 50$ sequences.

shared the most abundant OTUs overall and coincidentally the most abundant OTU of each other, the most abundant OTU of Stylissa carteri (OTU-3) was not encountered in any other sponge species. In addition to this, OTU-3 represented almost $82 \%$ of the S. carteri archaeal community (with 8858 sequences) suggesting that Cenarchaeum symbiosum is likely to make a most pronounced contribution to $S$. carteri functional aspects. Moitinho-Silva et al. (2014) also linked the dominant members of the microbial community of S. carteri to the highly expressed functions attributed to its microbiome. Cenarchaeum symbiosum has been reported either as a strict autotroph, or as a mixotroph using both carbon dioxide and organic material as carbon sources (Hallam et al. 2006). It is likely that these are the main functions performed by this organism in S. carteri.

Xestospongia testudinaria and A. lobata had similar OTU composition. The most abundant OTU overall (OTU-4) was exclusively found in $X$. testudinaria (2484 sequences) and $A$. lobata $(10,863)$. This OTU was assigned to the genus Nitrosopumilus. Nitrosopumilus maritimus has been reported as a chemolithoautotrophic archaeon, which aerobically oxidizes ammonia to nitrite (nitrification; Könneke et al. 2005). It is likely that these are the main functions performed by Nitrosopumilus members in both sponge species.

The most abundant shared OTUs were almost all $(2$, $5,6,7,11,20,301,759)$ assigned to the family Marine Group II (Euryarchaeota, Thermoplasmata, E2). The ecological role of the Marine Group II is still largely unknown due to the absence of cultured representatives of this group. It is believed that the organisms assigned to this group live heterotrophically (Zhang et al. 2015). Through the analysis of a nearly complete genome of a Marine Group II representative, Iverson et al. (2012) suggested these organisms are photo-heterotrophic, motile and polymer (lipids and proteins) degraders.

NSTI scores were generally low but higher for $X$. testudinaria and A. lobata. According to Langille et al. (2013), PICRUSt still produces accurate results for samples with a mean NSTI score of 0.17 . Here, all the mean NSTI values were lower than 0.17 , thus providing relatively accurate and interesting insights into putative archaeal community functioning.

In general $X$. testudinaria and $A$. lobata had a similar KO composition that was, in turn, distinct from that of S. carteri. Archaeal communities of $X$. testudinaria and A. lobata were similarly enriched in most pathways (Figure S4 and Figure 7). Based on the assumption that the prediction of the HMA-LMA status can be based on the microbiome profiles of sponges (Moitinho-Silva et al. 2017), these results, together with the above referred compositional similarity, suggest that $A$. lobata is a HMA sponge, although this remains to be proven.

According to LEfSe analysis, $X$. testudinaria showed a significant enrichment in seven of the 15 carbohydrate metabolism pathways namely glycolysis/gluconeogenesis, citrate cycle (TCA cycle), pentose and glucuronate interconversions and pyruvate, propanoate, pentose phosphate and starch and sucrose metabolisms (Figure 6). These results are in accordance with Freeman and Thacker (2011) and support the generally accepted idea that HMA sponges rely more heavily on their symbionts to acquire energy, and especially carbon, than LMA sponges, which rely more heavily on their high pumping rates (Weisz et al. 2007). Freeman and Thacker (2011) reported that Aplysina cauliformis and Neopetrosia subtriangularis (two HMA sponges) obtained about $77 \%$ of their carbon needs 


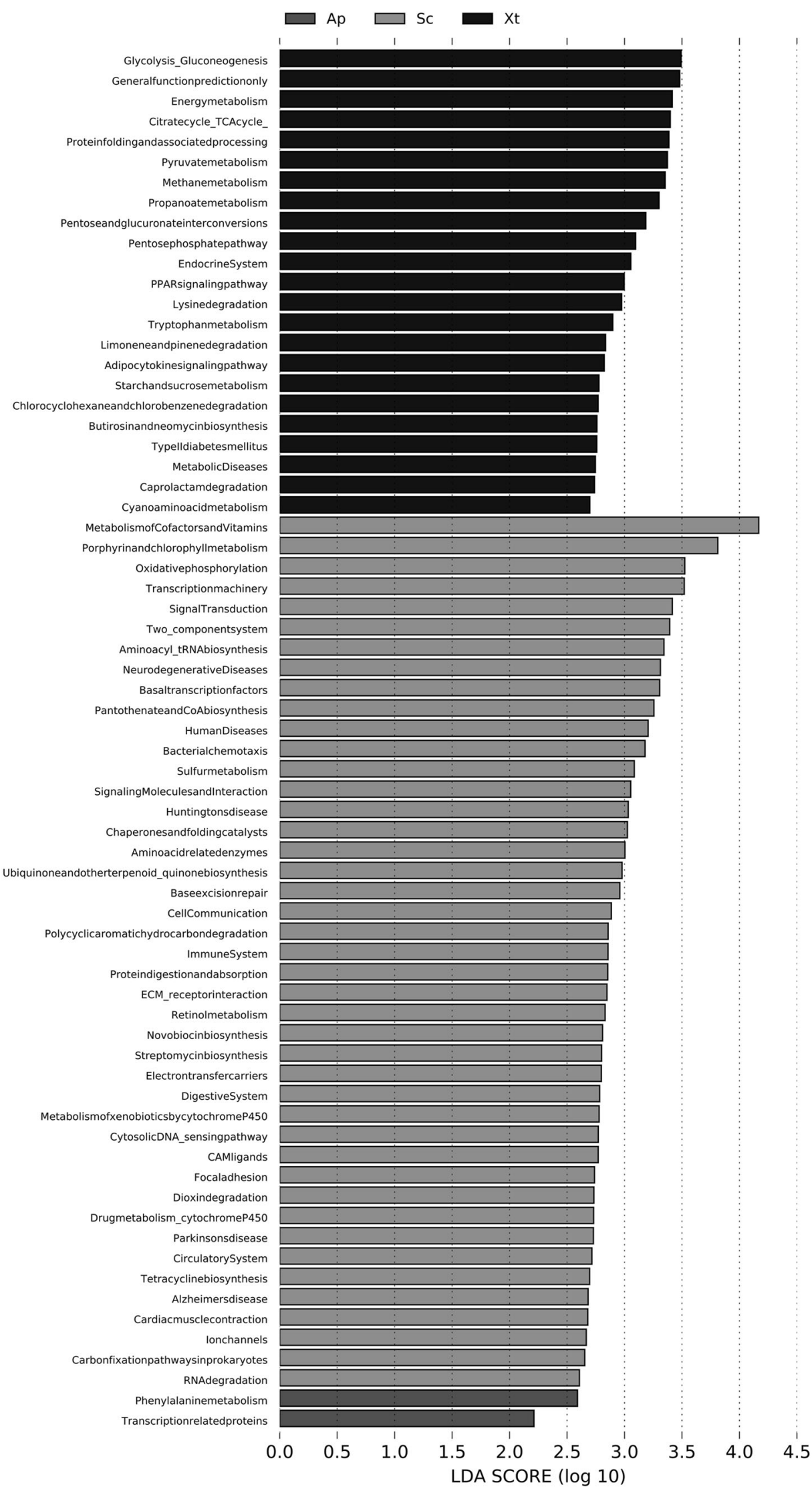

Figure 6. Histogram of the LDA scores ranking the statistically and biologically different archaeal categories, subcategories and pathways according to the effect size. KEGG categories, subcategories and individual pathways coloured dark grey indicate significant enrichment in A. lobata while those coloured light grey indicate significant enrichment in S. carteri and those coloured black indicate significant enrichment in $X$. testudinaria. 
a. Amin.Acid.Metab.
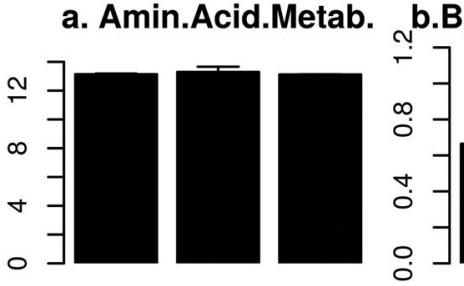

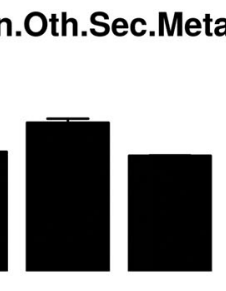

\author{
b.
}

c. Cell.Motility
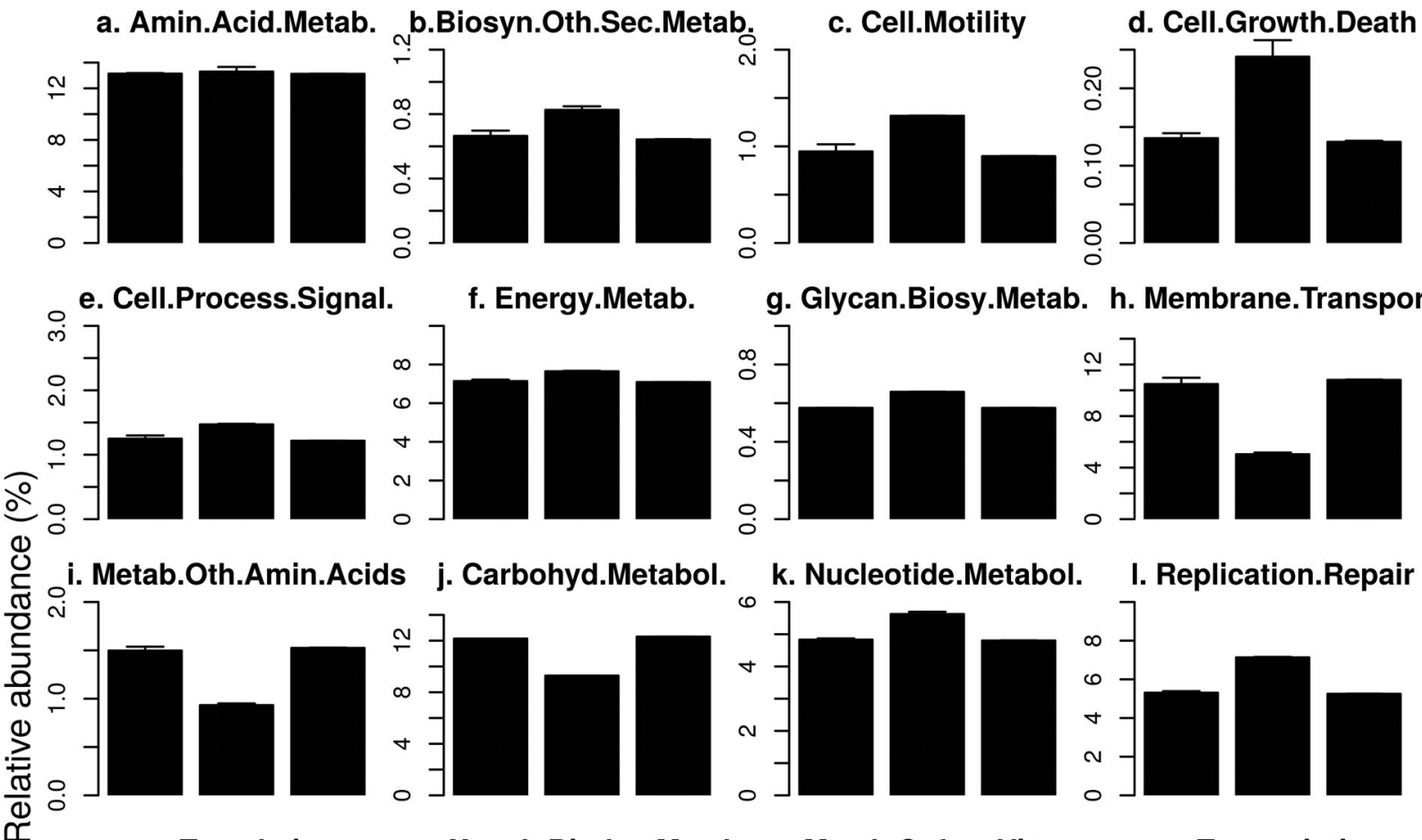

f. Energy.Metab.
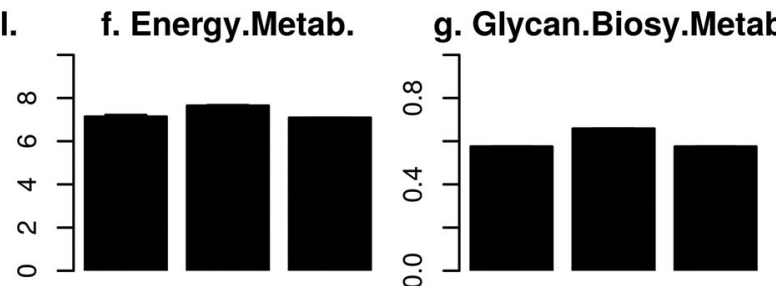

m. Translation
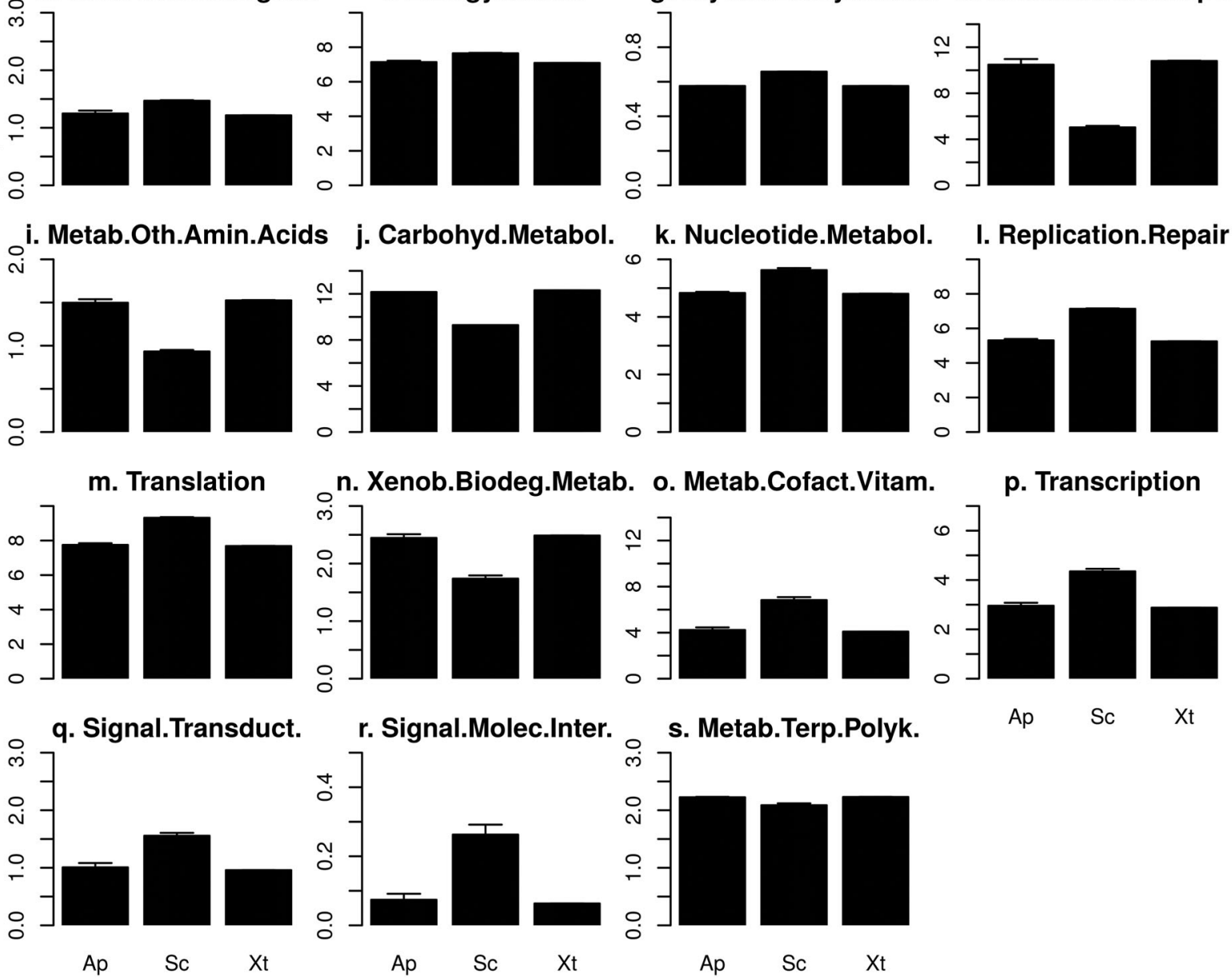

Figure 7. Mean relative abundance of predicted gene counts for selected functional individual pathways for samples from $S$. carteri (Sc), A. lobata (Ap) and X. testudinaria (Xt). Error bars represent a single standard deviation. The individual pathways shown include the following KEGG pathways: (a) Amino acid metabolism; (b) Biosynthesis of other Secondary Metabolites; (c) Cell Motility; (d) Cell Growth and Death; (e) Cellular Processes and Signalling; (f) Energy Metabolism; (g) Glycan Biosynthesis and Metabolism; (h) Membrane Transport; (i) Metabolism of other Amino Acids; (j) Carbohydrate Metabolism; (k) Nucleotide Metabolism; (I) Replication and Repair; (m) Translation; (n) Xenobiotics Biodegradation and Metabolism; (o) Metabolism of Cofactors and Vitamins; (p) Transcription; (q) Signal Transduction; (r) Signalling Molecules and Interaction; (s) Metabolism of Terpenoids and Polyketides.

from their microbial cells while only $27 \%$ is obtained by the LMA sponge Niphates erecta.

Additionally, $X$. testudinaria was also significantly enriched in pathways such as limonene and pinene degradation (metabolism of terpenoids and polyketides) and chlorocyclohexane, chlorobenzene and caprolactam degradation (xenobiotics biodegradation and metabolism). By degrading these compounds Archaea obtain energy and, at the same time, remove toxic compounds from the sponge host tissue. This may suggest sponges, and in particular $X$. testudinaria, as xenobiotic degraders and thus as bioremediators. The degradation of toxic compounds was previously associated with other sponge species, namely, Cymbastela coralliophila, Rhopaloeides odorabile and Cymbastela concentrica (Fan et al. 2012).

S. carteri samples were significantly enriched in genetic information processing pathways namely: transcription (basal transcription factors) and translation (aminoacyl-tRNA biosynthesis) pathways; and in 

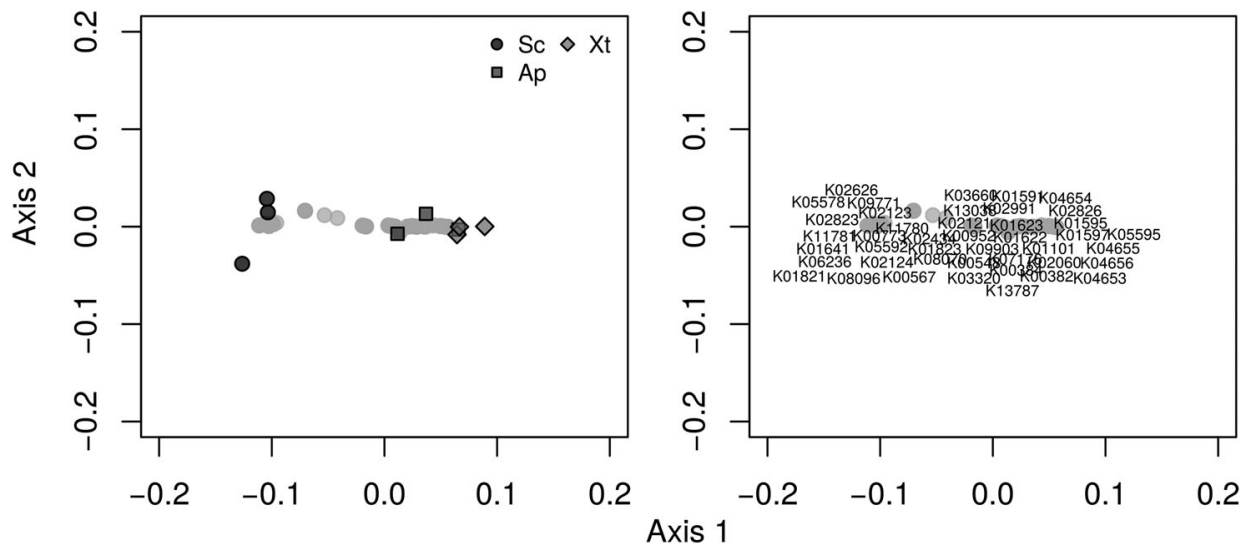

Figure 8. Ordination showing the first two axes of the PCO analysis for KO composition. Symbols represent samples from S. carteri (Sc), A. lobata (Ap), X. testudinaria (Xt). Numbers refer to KO numbers.

environmental information processing pathways (signalling molecules and interaction and signal transduction: two-component system).

Genetic information processing is particularly important when organisms are exposed to endogenous and/or exogenous factors that can damage DNA (Eggleston 2007). Previous studies have shown that sponge microbes were enriched in proteins related to stress responses (Thomas et al. 2010; Fan et al. 2012; Liu et al. 2012; Moitinho-Silva et al. 2014) and Fan et al. (2012) suggested that sponge symbionts acquired resistance mechanisms to deal with the stressful conditions found within the sponge environment. It is possible that due to their morphology and to the high volumes of water filtered by LMA sponges, these sponges represent a less protected and stable environment for Archaea than HMA sponges. Supporting this idea, S. carteri samples were enriched in signal transduction systems, which play important roles in the adaptation of organisms to new environmental conditions (sensing the environment and responding by altering gene expression) and thus predicted to be enriched in organisms living in unstable environments. The two-component system (part of the signal transduction system and also significantly enriched in S. carteri) has been reported as a system in which organisms respond, through gene regulation, to changes in nutrient (carbon, phosphorus, nitrogen, etc.) and oxygen availability in the environment (Chang and Stewart 1998; Oyserman et al. 2016a, 2016b).

The present study suggested the existence of a HMA/ LMA dichotomy in archaeal compositional and functional levels. The archaeal community of $A$. lobata was very similar to that of $X$. testudinaria both in terms of OTU and KO composition which suggests that A. lobata is a HMA sponge. This, however, needs to be confirmed in further studies. This study also suggests that some of the most enriched functions identified in the sponge archaeal communities may be related to the different morphologies and life strategies associated with LMA and HMA sponge species.

\section{Acknowledgements}

We are grateful for the support in the field by Misool Eco Resort, Andy Miners, Dadi, Christiaan de Leeuw, Purwanto and The Nature Conservancy.

\section{Disclosure statement}

No potential conflict of interest was reported by the authors.

\section{Funding}

This work was supported by European Funds through COMPETE - Operational Thematic Program for Competitiveness and Internationalization [FCOMP-01-0124-FEDER008657] and by National Funds through the Portuguese Foundation for Science and Technology (FCT) within the LESS CORAL project [PTDC/AAC-AMB/115304/2009] and the Ecotech-Sponge [PTDC/BIAMIC/6473/2014 - POCI-01-0145FEDER-016531]. Thanks are due for the financial support to CESAM (UID/AMB/50017 - POCI-01-0145-FEDER-007638), to FCT/MCTES through national funds (PIDDAC - Programme of investments and Expenditure of Development of the Central Administration), and the co-funding by the European Regional Development Fund (FEDER), within the PT2020 Partnership Agreement and Compete 2020. Francisco J.R.C. Coelho and Ana R.M. Polónia were supported by a postdoctoral scholarship (SFRH/BPD/92366/2013 and SFRH/BPD/ $117563 / 2016$ respectively) funded by FCT - Portuguese Foundation for Science and Technology within the Human Capital Operational Programme (HCOP), subsidized by the European Social Fund (ESF) and National funds MCTES. The Netherlands Organisation for Scientific Research provided funding to Leontine E.B. through the grant [RUBICON \#825.12.007 and VENI\#863.14.020]. 


\section{ORCID}

Daniel Francis Richard Cleary (D) http://orcid.org/0000-00026143-3390

\section{References}

Bayer K, Kamke J, Hentschel U. 2014a. Quantification of bacterial and archaeal symbionts in high and low microbial abundance sponges using real-time PCR. FEMS Microbiology Ecology. 89:679-690. doi:10.1111/15746941.12369

Bayer K, Moitinho-Silva L, Brümmer, F, Cannistraci CV, Ravasi T, Hentschel U. 2014b. GeoChip-based insights into the microbial functional gene repertoire of marine sponges (high microbial abundance, low microbial abundance) and seawater. FEMS Microbiology Ecology. 90:832-843. doi:10.1111/1574-6941.12441

Bell JJ. 2008. The functional roles of marine sponges. Estuarine, Coastal and Shelf Science. 79:341-353. doi:10. 1016/j.ecss.2008.05.002

Blanquer A, Uriz MJ, Galand PE. 2013. Removing environmental sources of variation to gain insight on symbionts vs. transient microbes in high and low microbial abundance sponges. Environmental Microbiology. 15:3008-3019.

Brochier-Armanet C, Boussau B, Gribaldo S, Forterre P. 2008. Mesophilic Crenarchaeota: proposal for a third archaeal phylum, the Thaumarchaeota. Nature Reviews Microbiology. 6:245-252. doi:10.1038/nrmicro1852

Brochier-Armanet C, Gribaldo S, Forterre P. 2012. Spotlight on the Thaumarchaeota. The ISME Journal. 6:227-230. doi:10. 1038/ismej.2011.145

Calcinai B, Bastari A, Bavestrello G, Bertolino M, Horcajadas SB, Pansini M, Makapedua DM, Cerrano C. 2017. Demosponge diversity from North Sulawesi, with the description of six new species. ZooKeys. 680:105-150.

Caporaso JG, Kuczynski J, Stombaugh J, Bittinger K, Bushman FD, Costello EK, Fierer N, Peña AG, Goodrich JK, Gordon Jl, et al. 2010. QIIME allows analysis of high-throughput community sequencing data. Nature Methods. 7:335-336. doi:10.1038/nmeth.f.303

Cebrian E, Uriz MJ, Garrabou J, Ballesteros E. 2011. Sponge mass mortalities in a warming Mediterranean Sea: are cyanobacteria-harboring species worse off? PLoS One. 6: e20211.

Chang C, Stewart RC. 1998. The two-component system regulation of diverse signaling pathways in prokaryotes and eukaryotes. Plant Physiology. 117:723-731. doi:10.1104/ pp.117.3.723

Cleary DFR, Becking LE, de Voogd NJ, Pires ACC, Polónia ARM, Egas C, Gomes NCM. 2013. Habitat- and host-related variation in sponge bacterial symbiont communities in Indonesian waters. FEMS Microbiology Ecology. 85:465482. doi:10.1111/1574-6941.12135

de Goeij JM, Van Oevelen D, Vermeij MJA, Osinga R, Middelburg JJ, de Goeij AFPM, Admiraal W. 2013. Surviving in a marine desert: the sponge loop retains resources within coral reefs. Science. 342:108-110. doi:10. $1126 /$ science.1241981

de Voogd NJ, Cleary DFR. 2008. An analysis of sponge diversity and distribution at three taxonomic levels in the thousand islands/Jakarta Bay reef complex, West-Java,
Indonesia. Marine Ecology. 29:205-215. doi:10.1111/j. 1439-0485.2008.00238.x

Diaz MC, Rützler K. 2001. Sponges: an essential component of Caribbean coral reefs. Bulletin of Marine Science. 69:535-546.

Edgar RC. 2013. UPARSE: highly accurate OTU sequences from microbial amplicon reads. Nature Methods. 10:996-998. doi:10.1038/nmeth.2604

Eggleston AK. 2007. DNA replication and repair. Nature. 447:923-923. doi:10.1038/447923a

Erwin PM, Coma R, López-Sendino P, Serrano E, Ribes $M$, Olson J. 2015. Stable symbionts across the HMA-LMA dichotomy: low seasonal and interannual variation in sponge-associated bacteria from taxonomically diverse hosts. FEMS Microbiology Ecology. 91:fiv115. doi:10.1093/ femsec/fiv115

Erwin PM, Thacker RW. 2008. Cryptic diversity of the symbiotic cyanobacterium Synechococcus spongiarum among sponge hosts. Molecular Ecology. 17:2937-2947. doi:10. 1111/j.1365-294X.2008.03808.x

Fan L, Reynolds D, Liu M, Stark M, Kjelleberg S, Webster NS, Thomas T. 2012. Functional equivalence and evolutionary convergence in complex communities of microbial sponge symbionts. Proceedings of the National Academy of Sciences. 109:E1878-E1887. doi:10.1073/ pnas.1203287109

Freeman CJ, Thacker RW. 2011. Complex interactions between marine sponges and their symbiotic microbial communities. Limnology and Oceanography. 56:15771586. doi:10.4319/lo.2011.56.5.1577

Freeman CJ, Thacker RW, Baker DM, Fogel ML. 2013. Quality or quantity: is nutrient transfer driven more by symbiont identity and productivity than by symbiont abundance? The ISME Journal. 7:1116-1125. doi:10.1038/ismej.2013.7

Giles EC, Kamke J, Moitinho-Silva L, Taylor MW, Hentschel U, Ravasi T, Schmitt S. 2013. Bacterial community profiles in low microbial abundance sponges. FEMS Microbiology Ecology. 83:232-241. doi:10.1111/j.1574-6941.2012.01467.x

Gloeckner V, Wehrl M, Moitinho-Silva L, Gernert C, Schupp P, Pawlik JR, Lindquist NL, Erpenbeck D, Wörheide G, Hentschel U. 2014. The HMA-LMA dichotomy revisited: an electron microscopical survey of 56 sponge species. The Biological Bulletin. 227:78-88. doi:10.1086/ BBLv227n 1 p78

Gomes NCM, Cleary DFR, Pinto FN, Egas C, Almeida A, Cunha A, Mendonça-Hagler LCS, Smalla K. 2010.Taking root: enduring effect of rhizosphere bacterial colonization in mangroves. PLoS One. 5:e14065-a. doi:10.1371/journal. pone.0014065

Gotelli NJ, Colwell RK. 2001. Quantifying biodiversity: procedures and pitfalls in the measurement and comparison of species richness. Ecology Letters. 4:379-391. doi:10. 1046/j.1461-0248.2001.00230.x

Hallam SJ, Konstantinidis KT, Putnam N, Schleper C, Watanabe YI, Sugahara J, Preston C, de la Torre J, Richardson PM, DeLong EF. 2006. Genomic analysis of the uncultivated marine crenarchaeote Cenarchaeum symbiosum. Proceedings of the National Academy of Sciences. 103:18296-18301. doi:10.1073/pnas.0608549103

Hentschel U, Fieseler L, Wehrl M, Gernert C, Steinert M, Hacker J, Horn M. 2003. Microbial diversity of marine sponges. In: Sponges (Porifera). Berlin, Heidelberg: Springer; p. 59-88. 
Hentschel U, Hopke J, Horn M, Friedrich AB, Wagner $M$, Hacker J, Moore BS. 2002. Molecular evidence for a uniform microbial community in sponges from different oceans. Applied and Environmental Microbiology 68: 4431-4440. doi:10.1128/AEM.68.9.4431-4440.2002

Hentschel U, Piel J, Degnan SM, Taylor MW. 2012. Genomic insights into the marine sponge microbiome. Nature Reviews Microbiology. 10:641-654. doi:10.1038/nrmicro2839

Hoffmann F, Radax R, Woebken D, Holtappels M, Lavik G, Rapp HT, Schläppy M-L, Schleper C, Kuypers MMM. 2009. Complex nitrogen cycling in the sponge Geodia barretti. Environmental Microbiology. 11:2228-2243. doi:10.1111/j. 1462-2920.2009.01944.x

Holmes B, Blanch H. 2007. Genus-specific associations of marine sponges with Group I Crenarchaeotes. Marine Biology. 150:759-772. doi:10.1007/s00227-006-0361-x

Iverson V, Morris RM, Frazar CD, Berthiaume CT, Morales RL, Armbrust EV. 2012. Untangling genomes from metagenomes: revealing an uncultured class of marine Euryarchaeota. Science. 335:587-590. doi:10.1126/science. 1212665

Jackson SA, Flemer B, McCann A, Kennedy J, Morrissey JP, O'Gara F, Dobson ADW, Virolle M-J. 2013. Archaea appear to dominate the microbiome of Inflatella pellicula deep sea sponges. PLoS One. 8:e84438. doi:10.1371/journal. pone. 0084438

Kamke J, Taylor MW, Schmitt S. 2010. Activity profiles for marine sponge-associated bacteria obtained by $16 \mathrm{~S}$ rRNA vs $16 \mathrm{~S}$ rRNA gene comparisons. The ISME Journal. 4:498508. doi:10.1038/ismej.2009.143

Könneke M, Bernhard AE, de la Torre JR, Walker CB, Waterbury JB, Stahl DA. 2005. Isolation of an autotrophic ammoniaoxidizing marine archaeon. Nature. 437:543-546. doi:10. 1038/nature03911

Langille MGI, Zaneveld J, Caporaso JG, McDonald D, Knights D, Reyes JA, Clemente JC, Burkepile DE, Vega Thurber RL, Knight $R$, et al. 2013. Predictive functional profiling of microbial communities using 16S rRNA marker gene sequences. Nature Biotechnology. 31:814-821. doi:10. 1038/nbt.2676

Lee OO, Wang Y, Yang J, Lafi F, Al-Suwailem A, Qian P-Y. 2011. Pyrosequencing reveals highly diverse and species-specific microbial communities in sponges from the Red Sea. The ISME Journal. 5:650-664. doi:10.1038/ismej.2010.165

Liu M, Fan L, Zhong L, Kjelleberg S, Thomas T. 2012. Metaproteogenomic analysis of a community of sponge symbionts. The ISME Journal. 6:1515-1525. doi:10.1038/ ismej.2012.1

McMurray SE, Pawlik JR, Finelli CM. 2014. Trait-mediated ecosystem impacts: how morphology and size affect pumping rates of the Caribbean giant barrel sponge. Aquatic Biology. 23:1-13. doi:10.3354/ab00612

Moitinho-Silva L, Seridi L, Ryu T, Voolstra CR, Ravasi T, Hentschel U. 2014. Revealing microbial functional activities in the Red Sea sponge Stylissa carteri by metatranscriptomics. Environmental Microbiology. 16:3683-3698. doi:10.1111/1462-2920.12533

Moitinho-Silva L, Steinert G, Nielsen S, Hardoim CCP, Wu YC, McCormack GP, López-Legentil S, Marchant R, Webster N, Thomas T, Hentschel U. 2017. Predicting the HMA-LMA status in marine sponges by machine learning. Frontiers in Microbiology. 8:32. doi:10.3389/fmicb.2017.00752
Oksanen J, Kindt R, Legendre P, O'Hara B, Simpson GL, Solymos $P$, Wagner H. 2009. Vegan: community ecology package. R Package Version. 1:15-14. http://www.cran.rproject.org/package=vegan

Oyserman BO, Moya F, Lawson CE, Garcia AL, Vogt $M$, Heffernen M, Noguera DR, McMahon KD. 2016a. Ancestral genome reconstruction identifies the evolutionary basis for trait acquisition in polyphosphate accumulating bacteria. The ISME Journal. 10:2931-2945. doi:10.1038/ismej.2016.67

Oyserman BO, Noguera DR, del Rio TG, Tringe SG, McMahon KD. 2016b. Metatranscriptomic insights on gene expression and regulatory controls in candidatus Accumulibacter phosphatis. The ISME Journal. 10:810-822. doi:10.1038/ismej.2015.155

Pires ACC, Cleary DFR, Almeida A, Cunha Â, Dealtry S, Mendonça-Hagler LCS, Smalla K, Gomes NCM. 2012. Denaturing gradient gel electrophoresis and barcoded pyrosequencing reveal unprecedented archaeal diversity in mangrove sediment and rhizosphere samples. Applied and Environmental Microbiology. 78:5520-5528. doi:10. 1128/AEM.00386-12

Polónia ARM, Cleary DFR, Freitas R, Coelho, FJRC, de Voogd NJ, Gomes NCM. 2016. Comparison of archaeal and bacterial communities in two sponge species and seawater from an Indonesian coral reef environment. Marine Genomics. 29:69-80. doi:10.1016/j.margen.2016.04.014

Polónia ARM, Cleary DFR, Freitas R, de Voogd NJ, Gomes NCM. 2015. The putative functional ecology and distribution of archaeal communities in sponges, sediment and seawater in a coral reef environment. Molecular Ecology. 24:409423. doi: $10.1111 / \mathrm{mec} .13024$

Polónia ARM, Cleary DFR, Freitas R, Gomes NCM, de Voogd NJ. 2017. Archaeal and bacterial communities of Xestospongia testudinaria and sediment differ in diversity, composition and predicted function in an Indonesian coral reef environment. Journal of Sea Research. 119:37-53. doi:10.1016/j. seares.2016.10.007

Polónia ARM, Cleary DRF, Duarte LN, de Voogd NJ, Gomes NCM. 2014. Composition of archaea in seawater, sediment and sponges in the Kepulauan Seribu reef system, Indonesia. Microbial Ecology. 67:553-567. doi:10.1007/ s00248-013-0365-2

Preston CM, Wu KY, Molinski TF, DeLong EF. 1996. A psychrophilic crenarchaeon inhabits a marine sponge: Cenarchaeum symbiosum gen. nov., sp. nov. Proceedings of the National Academy of Sciences of the USA. 93:6241-6246. doi:10.1073/pnas.93.13.6241

Ribes M, Dziallas C, Coma R, Riemann L. 2015. Microbial diversity and putative diazotrophy in high-and low-microbial-abundance Mediterranean sponges. Applied and Environmental Microbiology. 81:5683-5693. doi:10.1128/AEM.01320-15

Ribes $M$, Jimenez E, Yahel G, Lopez-Sendino P, Diez B, Massana R, Sharp JH, Coma R. 2012. Functional convergence of microbes associated with temperate marine sponges. Environmental Microbiology. 14:1224-1239 doi:10.1111/j.1462-2920.2012.02701.x

Schmitt S, Angermeier H, Schiller R, Lindquist N, Hentschel U. 2008. Molecular microbial diversity survey of sponge reproductive stages and mechanistic insights into vertical transmission of microbial symbionts. Applied and Environmental Microbiology. 74:7694-7708. doi:10.1128/ AEM.00878-08 
Schmitt S, Wehrl M, Bayer K, Siegl A, Hentschel U. 2007. Marine sponges as models for commensal microbe-host interactions. Symbiosis. 44:43-50.

Schöttner S, Hoffmann F, Cárdenas P, Rapp HT, Boetius A, Ramette, A, Gilbert JA. 2013. Relationships between host phylogeny, host type and bacterial community diversity in cold-water coral reef sponges. PLoS One. 8:e55505. doi:10.1371/journal.pone.0055505

Segata N, Izard J, Waldron L, Gevers D, Miropolsky L, Garrett WS, Huttenhower C. 2011. Metagenomic biomarker discovery and explanation. Genome Biology. 12:R60. doi:10.1186/ gb-2011-12-6-r60

Shannon E, Weaver W. 1949. The mathematical theory of communication. Urbana (IL): University of Illinois Press (125 pp).

Simpson TL. 1984. The Cell Biology of Sponges. New York: Springer-Verlag.

Steger D, Ettinger-Epstein P, Whalan S, Hentschel U, de Nys R, Wagner M, Taylor MW. 2008. Diversity and mode of transmission of ammonia-oxidizing archaea in marine sponges. Environmental Microbiology. 10:1087-1094. doi:10.1111/j. 1462-2920.2007.01515.x

Thomas T, Rusch D, DeMaere MZ, Yung PY, Lewis M, Halpern A, Heidelberg KB, Egan S, Steinberg PD, Kjelleberg S. 2010. Functional genomic signatures of sponge bacteria reveal unique and shared features of symbiosis. The ISME Journal. 4:1557-1567. doi:10.1038/ismej.2010.74
Turque AS, Batista D, Silveira CB, Cardoso AM, Vieira RP, Moraes FC, Clementino MM, Albano RM, Paranhos R, Martins OB, et al. 2010. Environmental shaping of sponge associated archaeal communities. PLoS One. 5:e15774. doi:10.1371/journal.pone.0015774

Webster NS, Taylor MW. 2012. Marine sponges and their microbial symbionts: love and other relationships. Environmental Microbiology. 14:335-346. doi:10.1111/j. 1462-2920.2011.02460.x

Weisz JB, Hentschel U, Lindquist N, Martens CS. 2007. Linking abundance and diversity of sponge-associated microbial communities to metabolic differences in host sponges. Marine Biology. 152:475-483. doi:10.1007/s00227-007-0708-y

Yahel G, Sharp JH, Marie D, Häse C, Genin A. 2003. In situ feeding and element removal in the symbiont-bearing sponge Theonella swinhoei: bulk DOC is the major source for carbon. Limnology and Oceanography. 48:141-149. doi:10.4319/lo.2003.48.1.0141

Zhang $C L$, Xie W, Martin-Cuadrado AB, Rodriguez-Valera F. 2015. Marine group II archaea, potentially important players in the global ocean carbon cycle. Frontiers in Microbiology. 6:1-9.

Zhang F, Pita L, Erwin PM, Abaid S, López-Legentil S, Hill RT. 2014. Symbiotic archaea in marine sponges show stability and host specificity in community structure and ammonia oxidation functionality. FEMS Microbiology Ecology. 90:699-707. doi:10.1111/1574-6941.12427 